\title{
A Virtual Dressing Room for People with Asperger's Syndrome
}

\section{A Usability Study to Realise Design Goals}

\author{
Line Gad Christiansen ${ }^{1}$, Anthony Lewis Brooks ${ }^{1}$, \\ Eva Petersson Brooks ${ }^{1}$, and Torben Rosenørn ${ }^{2}$ \\ ${ }^{1}$ Department of Architecture, Design and Media Technology \\ Aalborg University, Campus Esbjerg, Niels Bohrs Vej 8, 6700 Esbjerg, Denmark \\ ( $\operatorname{lgc}, \mathrm{tb}, \mathrm{ep})$ @create.aau.dk \\ ${ }^{2}$ Department of Learning and Philosophy \\ Aalborg University, Campus Esbjerg, Niels Bohrs Vej 8, 6700 Esbjerg, Denmark \\ tur@learning.aau.dk
}

\begin{abstract}
Using the Virtual Dressing Room ${ }^{1}$ (VDR) system, which is created as a research project between different companies and universities in Denmark and funded by the Danish National Advanced Technology Foundation, a usability study has been conducted with people with Asperger's Syndrome (AS), the initial aim was to determine if the people with AS would use the VDR system and understood it, as a second aim, the findings was used to determine a set of design goals. Seven teenagers with AS participated in the study, in the age range from 15 to 17 years old. A questionnaire was used before the study, to determine the target groups interests and how/if they purchase clothes. Through observations and video recording of the usability study, a qualitative interaction analysis provided a set of design goals to be used when designing for this target group. The goals emphasized the importance of an easy accessible and consistent solution with a limited amount of options and the importance of the user's own preferences.
\end{abstract}

Keywords: Asperger's Syndrome, Autism, Design Goals, Usability Study, Virtual Dressing Room, Virtual Environment, Questionnaire.

\section{Introduction}

A Virtual Dressing Room (VDR) is a solution enabling people to virtually check if a pieces of clothes fits in size. The VDR system used for this study is a part of a crossdisciplinary research project funded by the Danish National Advanced Technology Foundation, including Aalborg University in Esbjerg, Commentor A/S and Virtual

\footnotetext{
${ }^{1}$ The Danish National Advanced Technology Foundation:

http: //hoejteknologifonden.dk/projektgalleri/

6_juni_2011_17_nye_investeringer/det_digitale_proeverum/
} 
Lab A/S as partners $[1,2]$. The VDR targets a decreased amount of returned clothes purchased online. Through the usability study conducted for this research, the VDR also showed potential in other areas such as ADL for people with Asperger's Syndrome (AS), which is a condition under the autism spectrum disorder [3]. When being impaired by autism, social activities can be difficult $[3,4]$.

For people with AS, their intelligence level is normal to high, but their social competences and their ability to deal with changes is low [4]. They do not have the skills of putting themselves in the place of others, also called Theory of Mind, and hence they cannot understand why the people around them act as they do [5]. People with AS often perceive activities within social contexts, as challenging [4]. Attwood [6] further argues that people with AS can suffer from sensory overload and that daily activities can be challenging, which can affect situations such as shopping for clothes. This study addresses the question of designing a Virtual Dressing Room (VDR) targeting people with AS.

\section{Asperger's Syndrome}

The gender spread in the diagnostics of autism is 1 female to (at least) 6 males [7], and in the case of teenagers with autism, the girls often have it more difficult in relation to unknown situations and social context, they are more restricted to try out new things or enter new experiences than boys [6]. When introduced to new things, such as settings or people, individuals with AS perceive the world through a bottom-up mental model [4], meaning that they have difficulties generalizing sensory information, e.g. having to perceive all the information consciously before making an interpretation. This affects both their social life, their ability to interpret situations and, also, how comfortable they feel in new surroundings.

Attwood [6] stated that a person (especially when being young) with AS can overcompensate in social situations, by e.g. denying that there are any problems. The person believes or pretends that he never makes mistakes, never is wrong and that he must be listened to because of his high intelligence. In an effort to avoid looking stupid, the person with AS denies his social limitations which can result in behaviors such as dominance and arrogance [6].

According to Dautenhahn [7], when designing for children with autism, the differences between people with autism in a specific age need to be considered. Therefore, before initiating the design activity, the target group should be defined very clearly and the individual needs taken into account. The environment has to be safe, motivating and give the user a sense of being in control. People with autism have difficulties with having a holistic view on a situation (e.g. having different perspectives on one thing and consider all the perspectives before making a decision) [7].

\subsection{Shopping and AS}

Louis [8] argues that people with autism generally finds shopping situations uncomfortable, which is in line with results from a netnography study by the forum 
Wrongplanet.net, where several people with AS reported that they found shopping stressful and challenging. According to the netnography study, aspects such as lighting, sounds, smells and the open areas with a large amount of shoppers increased the stress level for people with AS. Hence a short shopping trip demanded a lot of energy from the person, with the result of them needing solitude the rest of the day.

Baas \& Raaij [13] researched how AS affects exploratory consumer behavior. They hypothesized that AS would affect consumer behavior negatively. Through a comparative study they concluded that their results supported their hypothesis [13]. They found that people with AS tend to:

- Repeat the same behavior more frequently

- Know and buy less new products and services

- Take fewer risks and be less adventurous

- Have a low preference for exploratory shopping behavior

- Communicate less with others about purchases

- Change brands less often with as the primary reason a preference for less change and variety $[13, \mathrm{p} .476]$

Clothes shopping are in this study is considered as an aspect of the Activities of Daily Living (ADL) [9]. According to Smith et al. [9], ADL for people with autism, including AS, can be difficult, especially in the area of personal care skills [10]. A to a pre-questionnaire, conducted before the usability study, including 13 participants, showed that people with AS enjoy using computers and consoles, which is in line with Chen \& Bernard-Opitz's study [11] and Putnam \& Chong's [12] survey. These preferences in technology are used as a basis for choosing the VDR as a possible solution for increased ADL. In this regard, the paper will, in particular, focus on the VDR as a safe and joyful virtual environment and will conclude with a set of design goals targeting users with Asperger's Syndrome (AS).

\subsection{Technology and AS}

Putnam \& Chong [12] did a survey to determine what people with autism want in relation to software and technology. They found that the people who responded to their survey (who were both people with autism and parents to children with autism), had three main areas that they wanted software and technology to support: (1) social/communication; (2) academic/school help (3) and scheduling/organization [12]. According to the authors, the development of a system should consider sensory integration and motivation. Furthermore, the majority of the responses from the target group indicated a main interest in computers and technology. Using a computer was also considered as a general strength for the people with autism [12].

\section{Method}

A usability study of the VDR system was conducted with the aim of both providing insights to the interactions with the system and what a designer should consider when 
designing towards this target group. A questionnaire responded by 13 participants, was send out before the usability study in order to determine the target groups interests and preference. Analysis of the usability study was compared to both the questionnaire and existing literature to generalize the findings.

\subsection{Technology}

For the usability study, a prototype of the VDR system that is being developed within the VDR research project was available and used. This prototype was an iteration of the front-end of the VDR, which is the part that the users are exposed to. However, it suffered from not being well functioning, e.g. it was difficult for some participants to navigate the system.

\subsection{Participants}

The usability study of the VDR system included seven teenagers, 15 to 17 years of age, with AS. The participants came from a Danish school, and knew each other before the study was conducted. The participants were joined by three teachers and pedagogues, which the participants knew from their daily routines at the school. Two of the participants were female and the remaining five subjects were male. According to the teachers accompanying the participants, they all suffered from Asperger's Syndrome in different degrees.

\subsection{Procedure}

In order to come up with a set of design goals a usability test of the VDR in a controlled environment was carried out, focusing on possibilities and constraints when people with AS were using the VDR system. Observations and video recordings were used for the data gathering, but as ethics was of a great concern, the interactions with the VDR were purely done on the participants' terms, e.g. in relation to how and when during the day that they wanted to interact with it and how long time they used interacting with the VDR. As people with AS has social impairments, easily get sensory overloads and experience new environments in another way than typically developed people, the ethics were prioritized. All the participants were presented with the VDR system at the same time in the morning of the day of the study, and they could then interact with it as they pleased in a time period of three hours, they were not forced in any way and all agreed to participate in the study beforehand. Parental information was sent out one week before the study.

The unit of analysis was the actions and interactions when using the VDR. In line with Petersson $[14,15,16]$, the preference was to design the shopping activities that most likely will lead to a desired shopping experience. The possibilities and constraints that can occur when designing these activities are all relative to the need of a more holistic view on this complex situation. In order to consider this complexity, we used interaction analysis [17], focusing on two aspects: (1) the attributes of the VDR; in what way the participants enhanced or decreased the (inter)action, and (2) the 
process and outcome when using the VDR; how the design enhanced or decreased the shopping experience.

Before the usability test, a questionnaire with 13 participants was used to determine what interests people with AS have and how they perceive shopping, both online and in stores. The respondents were both some of the participants for the usability study and people with AS from schools and living facilities in Denmark.

\section{$4 \quad$ Results}

\subsection{Questionnaire}

In the questionnaire used before the usability study, 10 out of the 13 participants were male, the majority of these were between the age of 15 and 19. The results from the questionnaire showed that the participants generally preferred to use computers in relation to their interest, e.g. for gameplay and other activities, such as watching movies. They dislike buying clothes, over 75 percent answered that buying clothes is one of the activities that they preferred the least. Seven out of the 13 participants mainly shops online for clothes, but does so rarely (less than one time per month). The main reason for buying clothes online are that it is quick, they do not have to buy the clothes from people and that you do not have to walk around in the shop, but all 13 participants responded that they need the sensation of the clothes and that this is the weakness of online shopping. This fits in line with Attwood [6] who states that people with AS suffers from sensory overload, and according to feedback from the test, the reason they need to feel the clothes is due to that a lot of fabrics used for clothes, tend to be itching for people with AS.

\subsection{Usability Study}

Throughout the usability study, the seven participants interacted with the VDR system as they pleased. They all entered the system, but only two of the participants tried the system multiple times, the others responded that they did not find clothes interesting, they disliked the clothes options, they found the system to be boring and not functioning well. The female participants mainly observed from a distance, which is in line with Attwood [6] who stated that girls with AS are more reluctant to try new things. After the study, the participants gave feedback about the system, 6 out of the seven participants replied that the system was boring.

\section{Discussion and Conclusions}

Due to the amount of participants, the study is explorative and conducted purely with a qualitative approach. Combined with the differences within the target group [7], the design goals extracted from the study can be restricted and not applicable to everyone with AS. As the participants were in a specific age group (teenagers), the design goals might differ if the study was conducted with another age group. 
As the female participants where reluctant and did not participate much, the design goals are mainly aiming towards the male participants, but as the gender ratio are 1:6, the findings could be generalized as the majority of the people with AS, are mainly male.

Speculations are that a participatory design of the interface and content, or a more user centred approach for the VDR, could show other tendencies and demands from the target group. It could also increase the level of interaction from the participants.

The results showed that the VDR system included both possibilities and constraints. It was found that too many options of clothes decreased the participants' willingness to interact with the VDR. However, being a technological alternative to an otherwise stressing situation was perceived as a positive opportunity for the participants, but they also reported that they required feedback targeting the sensation of the fabrics.

- One of the main aspects for designing for people with AS is that too many options and choices can become confusing. In this case, the clothes were not appealing and there were too many options of clothes for them to make a decision, resulting in the participants leaving the system. This was confirmed by one of the teachers when giving feedback to the system, stating that some of the participants had difficulties with deciding the clothes they wanted to choose; hence they chose the clothes that were shown in the system when they entered the system. One male participant entered the system after observing others trying the system, when he entered the clothes shown was a dress, and he did not change to another piece of clothes, resulting in a girl teasing him.

- The people with AS are very different from each other, both in behavior and interests, meaning that the system should accommodate the different interests in some way, unless only targeting a narrow group within the target group. This is in line with the findings from Dautenhahn [7].

- The content has to be concrete and easy accessible. The content should be concise as it could demotivate the user with AS otherwise. For the VDR system, the application did not fill out the screen and around it; there were different information and options not related to the VDR available, it was observed through the usability study that this had a negative effect on the user experience, in the way that they lost focus on the system.

- Consistency within the content of a system should be considered. People with AS are detail oriented [6], and through the usability study if was observed that even small inconsistencies would remove the users attention from the system and unto the inconsistency, such as small breaks in the system, the buttons being influenced by graphic noise in the room etc.

- There should be a possibility of changing the interaction or going back in the system at any point during the interactions with a system. For instance, when the picture button was activated, the user could not avoid for the picture to be taken, resulting in a lot of the participants leaving the field of interaction and then returning when the picture was taken. 
As the VDR system is a prototype and hence a work in progress, when developing a more finalized system, these findings could be implemented and another usability test conducted.

Acknowledgements. It should be acknowledged that the Danish National Advanced Technology Foundation contributed to this work, as did the Virtual Dressing Room project by providing a prototype of the front-end VDR system.

\section{References}

1. Gao, Y., Petersson Brooks, E.: Designing Ludic Engagement in an Interactive Virtual Dressing Room System - A Comparative Study. In: Marcus, A. (ed.) DUXU 2013, Part III. LNCS, vol. 8014, pp. 504-512. Springer, Heidelberg (2013)

2. Kristensen, K., Borum, N., Christensen, L.G., Jepsen, H.W., Lam, J., Brooks, A.L., Brooks, E.P.: Towards a Next Generation Universally Accessible 'Online Shopping-forApparel' System. In: Kurosu, M. (ed.) HCII/HCI 2013, Part III. LNCS, vol. 8006, pp. 418-427. Springer, Heidelberg (2013)

3. Attwood, T.: Strategies for improving the social integration of children with aspergers syndrome. Autism 4(1), 85-100 (2000)

4. Beyer, J.: Autisme i et Udviklingsperspektiv. Autismebladet 3 (2010)

5. Baron-Cohen, S., Leslie, A., Frith, U.: Does the autistic child have a "Theory of mind"? Cognition 21(1), 37-46 (1985)

6. Attwood, A.: The Complete Guide to Asperger's Syndrome. The Complete Guide to Asperger's Syndrome. Jessica Kingsley Publishers, London (2006)

7. Dautenhahn, K.: Design Issues on Interactive Environments for Children with Autism. In: Proceedings of ICDVRAT, 3rd International Conference on Disability, Virtual Reality and Associated Technologies, pp. 153-161 (2000)

8. Louis, M.M.: Walking the Walk: My Autistic Son and the Scholarship of Empathy. Womens Studies in Communication 31(2), 233-239 (2010)

9. Smith, L.E., Maenner, M.J., Seltzer, M.M.: Developmental Trajectories in Adolescent and Adults with Autism: the Case of Daily Living Skills. Journal of the American Academy of Child \& Adolescent Psychiatry 51(6), 622-631 (2012)

10. Pierce, K.L., Schreibman, L.: Teaching Daily Living Skills to Children with Autism in Unsupervised Settings Through Pictorial Self-management. Journal of Applied Behavior Analysis 27(3), 471-481 (1994)

11. Chen, S.H.A., Bernard-Opitz, V.: Comparison of Personal and Computer Assisted Instruction for Children with Autism. Mental Retardation 31(6), 368-376 (1993)

12. Putnam, C., Chong, L.: Software and Technology Designed for People with Autism: What do users want? In: Proceedings of the 10th International ACM SIGACCESS Conference on Computers and Accessibility, pp. 3-10 (2008)

13. Baas, T.H., Raaij, W.F.: Familiar or Risky: the Asperger Syndrome Affects Exploratory Consumer Behaviour. Journal of Economic Psychology 31(3), 471-477 (2010)

14. Petersson, E.: Non-formal Learning through Ludic Engagement with in Interactive Environments. Doctoral dissertation, Malmoe University, School of Teacher Education, Studies in Educational Sciences (2006) 
15. Petersson, E.: Editorial: Ludic Engagement Designs for All. Digital Creativity 19(3), 141144 (2008)

16. Brooks, E.P.: Ludic Engagement Designs: Creating Spaces for Playful Learning. In: Stephanidis, C., Antona, M. (eds.) UAHCI 2013, Part III. LNCS, vol. 8011, pp. 241-249. Springer, Heidelberg (2013)

17. Jordan, B., Henderson, A.: Interaction Analysis: Foundations and Practice. The Journal of the Learning Sciences 4(1), 39-103 (1995) 